\title{
LA ESCUELA DE SALAMANCA COMO PRECURSORA DE LA ECONOMÍA MODERNA: A.R.J. TURGOT
}

FERNANDO HERNÁNDEZ FRADEJAS*

\section{I \\ ANTECEDENTES HISTÓRICOS SALMANTINOS DE LA ESCUELA AUSTRIACA DE ECONOMÍA: UNA APROXIMACIÓN}

En los siglos XV y XVI hubo muchos cambios sociales y económicos importantes que hicieron reforzar la opinión de cómo los procesos de interacción social en el mercado funcionaban en la sociedad. En este sentido muchos teólogos y juristas se pusieron manos a la obra para poder describir lo que realmente estaba sucediendo en las sociedades de aquel entonces. Los movimientos comerciales y económicos se trasladaban con mucha mayor facilidad y las economías de todo el mundo empezaron a interrelacionarse con una frecuencia mucho más de lo habitual, ya sea por la necesidad de la plata americana o por los descubrimientos de artefactos técnicos por parte de China. La necesidad de dar una respuesta moral a estos acontecimientos o hechos económicos hizo que muchos teólogos, en su mayoría, se pusieran a describir los comportamientos que muchos individuos realizaban en el mercado. Según el profesor Lucas Beltrán (1987) «el economista austriaco Friedrich August von Hayek intuyó que en este grupo moralistas y teólogos salmantinos descubrieron la idea central de la concepción de la economía de mercado; es decir, que hay un orden natural en las actividades humanas. Además de las dos clases de órdenes en nuestro mundo; el orden físico y el orden jurídico,

* Doctorado en Economía. Universidad Rey Juan Carlos. 
existe un tercer orden superior, un orden económico y que fueron los miembros de la Escuela de Salamanca los primeros en intuirlo». El profesor Juan Velarde (2002) indica la necesidad de materializar jurídicamente la existencia de ciertos comportamientos pautados como son las instituciones que se van creando a la sazón del progreso económico, así como las incipientes letras de cambio o la contabilidad por partida doble de una manera mucho más formalizada y sistemática.

Al final de un largo período de debates científicos entre los distintos Historiadores del Pensamiento Económico en torno a las aportaciones que realizaron nuestros escolásticos del siglo de Oro español, se puede decir que contribuyeron significativamente en las siguientes áreas de estudio como, por ejemplo, la teoría subjetiva del valor, la teoría cuantitativa del dinero, la competencia como un proceso de rivalidad entre los vendedores, el redescubrimiento de la preferencia temporal, el carácter profundamente distorsionador que tiene la inflación sobre la economía real, la doctrina general del interés y una incipiente teoría de los cambios, entre otras.

La uniformidad de opinión alrededor de la formación de cómo debería llamarse a este grupo de intelectuales que reflexionaron sobre los temas económicos que anteriormente me he referido, tiene diversas opiniones o voces al respecto. Así tanto el profesor Jesús Huerta de Soto ${ }^{1}$ (2000, pp. 61-62) como la historiadora Marjorie Grice-Hutchinson ${ }^{2}$ (1989, pp. 21-25) identifican a estos teólogos y moralistas como la llamada Escuela de Salamanca. ${ }^{3}$ Por

${ }^{1}$ Al expresar: «La tradición del pensamiento económico de la Escuela Austriaca tiene, pues, sus orígenes intelectuales en España y más concretamente en una escuela, la de Salamanca, que, al igual que la moderna Escuela Austriaca, y en hondo contraste con el paradigma neoclásico, se caracteriza sobre todo por su gran realismo y rigor en sus supuestos analíticos».

${ }_{2}$ Grice-Hutchinson sugiere literalmente lo siguiente al indicar: «...yo quisiera sugerir que se siga empleando el nombre de la «Escuela de Salamanca», consagrado ya por varias generaciones de historiadores, para referirse específicamente a Francisco de Vitoria, sus colegas, sus discípulos y sus principales continuadores, así en el campo económico como en el de las otras disciplinas a que dedicaron mayormente sus esfuerzos».

${ }^{3}$ Ver el discurso de ingreso en la Real Academia de Ciencias Morales y Políticas de don José Larraz titulado «El cuantitativismo monetario de Salamanca» donde se emplea por vez primera la expresión Escuela de Salamanca. 
contra otros autores como Alejandro Chafuen expresan que el nombre de «Escuela de Salamanca» no es del todo exacto, por consiguiente subraya que "Often, the Hispanic Scholastics are referred to as the "School of Salamanca»....While many of the Hispanic Scholastics studied or taught in Salamanca, it is also true that some of the most important Scholastic authors studied at other Spanish universities, such as the Complutense at Alcalá de Henares (Imprecisión porque nunca ha existido la Universidad Complutense de Madrid en Alcalá de Henares). It is, therefore, more accurate to describe this group of Spanish thinkers as «Hispanic Scholastics». En este sentido el autor Oreste Popescu (1982, pp. 235-286) sigue con la misma línea argumental que su compatriota Alejandro Chafuen. Una importante voz autorizada como es la del maestro Don Luciano Pereña indica que los maestros del pensamiento político español son Francisco de Vitoria, Diego de Covarrubias, Martín de Azpilcueta y Domingo de Soto atribuyéndoles el nombre de «escuela salmantina, la escuela española del derecho internacional, los doctores de Salamanca, los maestros de Salamanca, o sencillamente "la escuela" (Pereña Vicente, 1954, pp. 17-42).

Finalmente y sin ánimo de agotar el tema, éstos son los autores más destacables, pero no por ello los más importantes, acerca de las contribuciones y trabajos de estudio que surgieron para estudiar a nuestros escolásticos en la producción de pensamiento económico. Entre éstos, cabe destacar a autores españoles como el Padre Venancio Carro, el Padre Beltrán Heredia, el Padre Demetrio Iparraguirre, el Padre Gorosquieta Reyes, José Larraz, Alberto Ullastres, Carmelo Viñas y Mey, Jaime Carrera Pujal, el maestro Luciano Pereña, Restituto Sierra Bravo, el Padre Francisco Gómez Camacho y al profesor Jesús Huerta de Soto. Por otro lado podemos destacar a autores extranjeros como James Brown Scott, Ernst Nys, Martin Grabmann, Wilhem Endemann, André Sayous, Bernard Dempsey, Joseph Schumpeter, Raymond de Roover, Wilhem Weber, John Noonan, Pierre Vilar, Bary Gordon, Alejandro Chafuen, Oreste Popescu, y a los tres últimos grandes maestros principales en esta materia como son Marjorie GriceHutchison, Murray Newton Rothbard y el premio Nobel de Economía Friedrich August von Hayek. 


\section{II \\ DESDE LA MORAL Y EL DERECHO HASTA LA CIENCIA DE LA TEORÍA ECONÓMICA}

Muchos de los economistas actuales que quieren adentrarse en el estudio del pensamiento económico de los miembros de nuestra escolástica tardía española se encuentran con ciertos problemas a la hora de afrontar el estudio debido a diversas causas, generalmente por razones epistemológicas o docentes a la hora de abordar los problemas económicos y sociales a tratar en este período histórico concreto.

Sin embargo este análisis, haciendo un inciso, no nos debería de generar problemas ya que el arsenal teórico-analítico que nos proporciona la Escuela Austriaca de Economía nos resuelve dichos problemas de raíz. Sólo con un conocimiento previo de ciertos conocimientos teóricos podemos interpretar los hechos históricos que es el objeto de debate a tratar aquí. En este sentido cabe destacar los avances significativos cuando este diálogo ética/moral vs. economía empezó a producirse en el primer tercio del siglo XX a raíz del protagonismo de la voz de la ciencia económica como mediador entre la ética y moral (Arrow, 1951; Keynes, 1988). Un dato significativo han sido las últimas revelaciones que han surgido por parte de la renovación de la teología moral en el postconcilio, dejando de hacer un necesario análisis riguroso y profundo sobre el contexto que la moral escolástica aportó realmente a la historia del pensamiento económico español.

III

LAS RAÍCES DEL CAPITALISMO Y LA INFLUENCIA NEGATIVA DE MAX WEBER Y ADAM SMITH: LA INOCULACIÓN DE LA TEORÍA DEL VALOR TRABAJO

Hay una opinión bastante extendida, sobre todo por América Latina (Cristaldo Ayala, 2006), donde la idea y el concepto de capitalismo suele ser objeto de calumnias e insultos por la errónea idea de que es más propio de protestantes y anglosajones. Este error nace de quien se puede considerar el fundador de la 
sociología moderna, es decir Max Weber. En su obra más importante titulada «La ética protestante y el espíritu del capitalismo» en 1905, este sociólogo señala que, en contraste con los países del norte de Europa, la Europa Mediterránea, romana, griega y tomista estaba condenada a vivir en la pobreza por sus raíces y bases católicas. Nada más lejos de la realidad. Los últimos hechos corroboran que los países católicos europeos progresaron con la economía de mercado y el capitalismo mucho más que los países protestantes.

Y no sólo eso. Max Weber tiene una interpretación incorrecta sobre cuáles fueron los verdaderos orígenes del capitalismo. Según parece no tuvo conocimiento de que los principios teóricos del liberalismo económico surgieron mucho antes que el calvinismo. Así varios escolásticos, en su mayoría dominicos y jesuitas, docentes de moral y teología en la Universidad de Salamanca, descubrieron y afianzaron estas bases en el siglo XVI. Es decir, dos siglos antes de los escritos del tan conocidísimo Adam Smith según apunta Rothbard en su Historia del Pensamiento Económico. De este modo el triunfo del protestantismo y la influencia de la Escuela Clásica de Economía y sus discípulos hicieron caer en el olvido aquellas contribuciones y enseñanzas que articularon ya de una manera originaria nuestros miembros de la Escuela de Salamanca.

La contribución principal de reducir todo a la teoría del valortrabajo de Adam Smith permitió poner en bandeja a Marx lo que él llamaría después la teoría socialista de la explotación. Según Rothbard, Adam Smith rompió con el laissez faire radical de sus más inmediatos antecesores - la distinción entre actividades productivas/improductivas (Infantino, 2000, pp. 278 y ss.), prohibición de la usura- como son nuestros escolásticos, penetrando un liberalismo muy tibio que muchos teóricos «socialdemócratas» de hoy podrían incluso aceptar (Huerta de Soto, 2000, pp. 60-61). 


\section{IV \\ DE ITALIA A ESPAÑA: LA GENERACIÓN DEL ESCOLASTICISMO TARDÍO ESPAÑOL}

La figura en Italia que hizo renacer un tomismo con fuerza y empuje fue el señor Tomás de Vío, el famoso Cardenal Cayetano (1468-1534). Dominico de gran importancia, llegó a ser General de la Orden de los Dominicos y fue uno de los defensores encargados por el Papa en los debates con el famoso protestante Martin Lutero. En su Comentario a la Summa de Aquinate, Cayetano indica la difundida opinión escolástica de que el justo precio es el precio común de mercado, el que refleja la estimación de compradores y vendedores, y añade además que el precio variará al cambiar las condiciones de la oferta y la demanda. En su obra $D e$ cambiis (1499), defiende una plausible postura respecto al mercado de divisas argumentando la siguiente conclusión; dado que el papel del comerciante es legítimo, no podría ser menos la figura del cambista también puesto que se ocupa simplemente de una clase particular de transacción de mercancías. Además de explicar que el valor de la moneda no sólo depende de las condiciones actuales de la oferta y demanda de moneda, incorporó un elemento imprescindible que después sería incorporado como un elemento de la acción humana; es decir las expectativas (Huerta de Soto, 2001, p. 46). Otros temas notables abordados fueron tanto las figuras del préstamo como del interés, pero no con tanta brillantez.

Si en Italia fue el Cardenal Cayetano la persona encargada de tomar este renacido tomismo liberal, en España Francisco de Vitoria tuvo la suerte de ser la persona encargada de seguir con esta tradición escolástica. Francisco de Vitoria (1485-1546), gran teórico del derecho y pionero en la disciplina del derecho internacional, fue un profesor muy destacado e influyente. Aunque no se centró exactamente en cuestiones económicas, estuvo ampliamente interesado en la moralidad del comercio y sus opiniones siguieron la principal tradición escolástica. Subrayó que el precio justo es el común del mercado, aunque de haber un precio legalmente establecido, éste también ha de ser considerado justo, respetando así la legalidad vigente en cada momento. No 
siguió la teoría del valor objetivo al establecer que el coste de producción no fuera determinante, siguiendo así la antigua tradición del laissez-faire del derecho romano, en el cual el precio justo es el libremente acordado por las partes. También existe la obligación científica de estudiar a uno de los más importantes discípulos de Francisco de Vitoria, el también dominico Domingo de Soto (1494-1560). Fue profesor en la Universidad de Salamanca, además de prior en el Convento de San Esteban durante varias veces, teniendo el honor de ser el representante del Emperador Carlos V en el concilio de Trento, momento decisivo para la Contrarreforma católica. Su obra fue muy extendida, con muchas reimpresiones en varias de sus obras. Sin embargo, en temas de teoría económi$\mathrm{ca}$, no estamos de enhorabuena. Sus contribuciones no estuvieron a la altura. Aunque expresaba que «el precio de los bienes no lo determina su naturaleza, sino la medida en que sirven a las necesidades de la humanidad», debilitó su argumento haciendo grandes concesiones al «trabajo, esfuerzos y riesgos» implicados en la venta. De Soto, más que ningún otro, se inclinó por el estatismo frente a la determinación de los precios por el mercado y en contra de la cooperación espontánea del mercado.

Afortunadamente, otro distinguidísimo discípulo de Vitoria contrarrestó la influencia de De Soto. Éste fue Martín de Azpilcueta, llamado también doctor navarro. Ingresó en la orden de los Dominicos e introdujo nuevos aires renovadores para impulsar el liberalismo económico. La contribución más importante de Martín de Azpilcueta estuvo ligada a la teoría cuantitativa del dinero; así en su Comentario resolutorio de usuras (1556), ofreció una explicación perfecta al explicar que el valor de la moneda varía en relación inversa con su oferta o cantidad de moneda disponible. Martín de Azpilcueta señaló que «toda mercancía de la que hay fuerte demanda y débil oferta se encarece. La moneda, en cuanto puede ser vendida, trocada o intercambiada mediante algún tipo de contrato, es también una mercancía, por lo que se encarece cuando su demanda es grande y pequeña su oferta» (Rothbard, 1999, p. 138). Quizá otra importante aportación del doctor navarro fue el descubrimiento de la preferencia temporal el cual se basa en que, a igualdad de circunstancias, se valorarán más los bienes presentes que los bienes futuros, aunque Giles de Lessines 
mucho antes que él subrayó la importancia de esta idea al decir «que los bienes futuros no se valoran tanto como los mismo bienes disponibles de inmediato, ni tienen la misma utilidad para sus poseedores. Por esta razón su valor de acuerdo con la justicia ha de ser más reducido» (Huerta de Soto, 2000, p. 56).

Por último otro estudioso escolástico digno de mencionar fue Juan de Medina (1490-1546). Profesor de teología en la Universidad de Salamanca, hizo una espléndida argumentación a favor del cobro de intereses sobre un préstamo lo cual es totalmente legítimo si equivale a una compensación que se hace al prestamista por el riesgo de impago. El razonamiento de Medina es brillante: exponer la propiedad privada «al riesgo de que pueda perderse es algo que puede venderse, y comprarse, a un precio, no se cuenta entre las cosas que se hacen gratuitamente». El argumento era perfecto pero Medina debilitó su argumento sin saberlo al admitir que el cobro por riesgo de impago destruiría por completo la prohibición de la usura. Así muchos teólogos como Domingo de Soto pusieron el grito en el cielo defendiendo una postura totalmente contraria (Rothbard, 1999, p. 138).

\section{$\mathrm{V}$ \\ DIEGO DE COVARRUBIAS Y LEYVA}

Quizá por importancia, como figura destacable es Diego de Covarrubias y Leyva. Nació en 1512, fue hijo de un famoso arquitecto y llegó a ser obispo de la ciudad de Segovia (en cuya catedral se encuentra enterrado), además de haber sido ministro con el Rey Felipe II durante varios años. En la actualidad cuelga un retrato en el Museo del Greco, en Toledo, donde se pueden apreciar sus particulares y marcadas facciones. Muchos estudiosos consideran a Covarrubias como el mejor jurista después de Vitoria, siendo el alumno más destacado de Martín de Azpilcueta. Entre diversos cargos, adquirió gran importancia al ser nombrado Presidente del Consejo de Castilla.

Sus aportaciones a la teoría económica se marcan por haber desarrollado la teoría del valor subjetivo a partir de que San Bernardino de Siena y Johannes Nider se ocuparán de ella ya en el siglo XV, 
siendo Covarrubias la persona que siguió definitivamente en esta línea de trabajo. Así en sus Variarum (1554), recuperaría la teoría del valor al camino correcto: explicando que el valor de los bienes en el mercado viene determinado por la escasez y la utilidad; así pues no depende de las propiedades intrínsecas o materiales del objeto en cuestión, sino de la propia estimación subjetiva de los consumidores. Así dice: «El valor de un artículo no depende de su naturaleza esencial sino de la estimación humana, aun cuando ésta fuera estúpida. Por ejemplo, en las Indias el trigo es más caro que en España porque allí lo estiman más, aunque la naturaleza del trigo sea la misma en ambos lugares» (Huerta de Soto, 2000 , p. 54). No obstante, subraya que el precio justo de un bien no debe atribuirse a su coste original, ni a su coste en términos de horas de trabajo, sino sólo a su valor corriente en el mercado; por lo que, a igualdad de circunstancias, los precios caen si los compradores son pocos y los bienes abundantes, y viceversa. Destacable es la gran influencia que Covarrubias tuvo en Hugo Grocio, jurista protestante holandés del siglo XVII, como también en Italia donde fue ampliamente citado por Ferdinando Galiani. De este modo Huerta de Soto afirma que este escolástico llegó a anticipar muchas de las conclusiones teóricas sobre la teoría cuantitativa del dinero que posteriormente expondrían Martín de Azpilcueta y Juan de Mariana, entre otros.

\section{VI}

\section{LUIS SARAVIA DE LA CALLE}

Luis Saravia de la Calle, El Veronés, fue un contemporáneo de Diego de Covarrubias y Leyva, prolífico escritor de manuales de teología moral tomados de los grandes teólogos de la época, los adaptaba a las necesidades de confesores y penitentes. En su increíble obra Instrucción de Mercaderes, escrita en castellano antiguo, explica que cualquier teoría del valor basada en el coste de producción no es correcta ya que sólo según su utilidad y demanda en el mercado con escasez de oferta, se puede determinar lo que ellos denominaban el precio común de mercado, o sea, el precio justo. En 1544, expresó que «los que miden el justo precio de la cosa según 
el trabajo, costas y peligros del que trata o hace la mercadería yerran mucho; porque el justo precio nace de la abundancia o falta de mercaderías, de mercaderes y de dineros, y no de las costas, trabajos y peligros. Si hubiéramos de considerar el trabajo y el riesgo para calcular el precio justo, entonces ningún mercader sufriría jamás pérdidas, ni recibirían atención la abundancia o escasez de bienes y dinero» (Rothbard, 1999, p. 142). Obra bastante influyente tanto en España como en Italia, un discípulo llamado A.M. Venusti realizó un tratado muy parecido al de su maestro Saravia de la Calle. Obviamente las consideraciones del trabajo de Saravia de la Calle son considerables al refutar mucho tiempo antes la teoría objetiva del valor que sería desarrollada por los teóricos de la Escuela Clásica Anglosajona y que posteriormente tomaría Karl Marx y sus discípulos para elaborar la famosa teoría de la explotación.

\section{VII \\ TOMÁS DE MERCADO}

Tomás de Mercado escribió un famoso manual de Teología moral titulado Tratos y contratos de mercaderes (Salamanca, 1569), en segundo orden de importancia después del libro escrito por Saravia de la Calle. Se crió en México e ingresó en la orden de los Dominicos, regresando posteriormente a Salamanca y Sevilla para instalarse definitivamente en España. Mercado fue un teórico muy brillante en general. Llegó a aplicar el análisis de la utilidad a la moneda hasta casi descubrir el análisis marginal cuando subrayó que el poder de compra de la moneda es más elevado donde ésta es escasa y por tanto es «estimada» en más (Rothbard, 1999, p. 142). Destacable son también sus trabajos en el campo de la teoría bancaria y monetaria indicando que los depositantes deben pagar a los banqueros por el trabajo de guardarles sus depósitos de dinero, concluyendo que «de todos es regla común y general poder llevar salario de los que consignan en su banco dinero, o un tanto cada año o tanto al millar, pues les sirven y guardan su hacienda» (Huerta de Soto, 2002, p. 83). 
Otro autor muy importante dentro de nuestro grupo de escolásticos es el jesuita Luis de Molina. Estuvo destinado en Portugal después de una breve estancia en Salamanca y fue un gran autor con importantísimas aportaciones a la teoría económica desde un punto de vista liberal. Teórico monetario, defendió que la oferta y la demanda determinan el precio e impulsó la teoría de los tipos de cambio basada en la paridad del poder de compra de la unidad monetaria. Atacó con gran decisión el control del gobierno sobre los tipos de cambio y obtuvo gran reconocimiento en la recuperación de la teoría activa de los derechos naturales y de los derechos de propiedad (Rothbard, 1999, p. 146). Entendió el concepto dinámico de la competencia como «el proceso de rivalidad entre compradores que tiende a elevar el precio» aunque su aportación más importante fue el descubrimiento de que los depósitos y en general el dinero bancario, que él denomina chirographis pecuniarum, forma parte, al igual que el dinero en efectivo, de la oferta monetaria (Huerta de Soto, 2000, p. 58). La idea esencial recogida por Molina en 1597, antes que Mark Pennington en 1826, se explicó de la siguiente manera; el volumen total de transacciones monetarias que se efectúa en un feria no podría pagarse con la cantidad de dinero en metálico que en la misma cambia de manos, sino fuera por la utilización del dinero que generan los bancos mediante las anotaciones de sus depósitos y la emisión de cheques con cargo a los mismos por parte de los depositantes. De manera que, como resultado de la actividad financiera de los bancos, se crea de la nada una nueva cantidad de dinero en forma de depósitos que es utilizada en las transacciones (Huerta de Soto, 2000, p. 58).

IX

\section{JUAN DE MARIANA}

Si hay alguna persona en particular que se merezca un premio por reunir todas las características como miembro de la Escuela de Salamanca, éste debería ser Juan de Mariana. De Mariana fue 
un jesuita controvertido y bastante independiente durante toda su vida. Su obra, como no podría ser menos, fue brillante y espectacular. Denunció los efectos distorsionadores de la inflación, entendida como toda política estatal de crecimiento de la masa monetaria. Así en su «De monetae mutatione», traducido al castellano como Tratado y discurso sobre la moneda de vellón que al presente se labra en Castilla y de algunos desórdenes y abusos, criticó la política consistente en rebajar el componente metálico de la moneda de vellón iniciado por los gobernantes de la época; por consiguiente explicó cómo los efectos de la misma son el incremento de los precios y el caos generalizado. Además criticó el establecimiento de precios máximos para luchar contra los efectos de la inflación pues generaría sólo efectos negativos y muy contraproducentes. Además, Mariana escribió una joya titulada Discurso sobre las enfermedades de la compañia, publicada con carácter póstumo en 1625. En este libro trata de explicar cómo es totalmente imposible que un gobierno o cualquier tipo de organización se pueda hacer con la información de primera mano para poder organizar la sociedad civil en base a mandatos coactivos, y ello por una simple falta de información. De esta manera Mariana explica en relación con el gobierno que «es gran desatino que el ciego quiera guiar al que ve», añadiendo que los gobernantes «no conocen a las personas, ni los hechos, a lo menos, con todas las circunstancias que tiene, de que pende el acierto. Forzoso es que se caiga en yerros muchos, y graves, y por ello se disguste la gente, y menosprecie gobierno tan ciego» finalizando que "es loco el poder y mando», y que cuando «las leyes son muchas y en demasía; y como no todas se pueden guardar, ni aun saber, a todas se pierde el respeto» (Huerta de Soto, 2000, p. 59).

\section{$X$ \\ JUAN DE LUGO Y JUAN DE SALAS}

Nacido en 1583, de Lugo se preguntó cuál sería el precio de equilibrio, y ya en 1643 concluyó que depende de tan gran cantidad de circunstancias específicas que sólo Dios puede conocerlo 
— «pretium iustum mathematicum licet soli deo notum»-(Huerta de Soto, 2000, p. 56). Contemporáneo de Juan de Lugo, en 1617 Juan de Salas se refirió a las posibilidades de que un gobernante pueda llegar a conocer la información específica que dinámicamente se crea, descubre y maneja en el mercado, afirmando que «quas exacte comprehendere et pondedare Dei est non hominum», es decir, que sólo Dios, y no los hombres, puede llegar a comprender y ponderar exactamente la información y el conocimiento que se maneja en el proceso de mercado por los agentes económicos con todas sus circunstancias particulares de tiempo y lugar (Huerta de Soto, 2000, p. 56).

\section{XI \\ VIDA Y OBRA DE A.R.J. TURGOT (1727-81)}

Tuvo una obra muy importante desde el punto de vista de la teoría económica. Su trabajo más conocido fue el libro de Reflexiones sobre la formación y distribución de la riqueza (1766) que sumaba tan sólo cincuenta y tres páginas. Fue un estudiante brillante graduándose con honores. En principio su carrera profesional se dirigía para ser miembro del cuerpo eclesial aunque finalmente decidió unirse a la carrera burocrática. Dentro de ésta llegó a ser Inspector General de Finanzas, o lo que es lo mismo, Controlador General de Francia. Vincent de Gournay fue su maestro y justamente de éste recogió su gran aprecio al laissez-faire. Su maestro fue la persona encargada de difundir entre los distintos movimientos intelectuales las obras de Richard Cantillon.

Aunque se le suela situar en la historia del pensamiento económico cerca de los fisiócratas, Rothbard indica que la comprensión de la teoría económica de Turgot supera a la de los fisiócratas y que en temas como el capital e interés todavía no ha sido igualado (Rothbard, 1999, p. 426). Se anticipa a Frédéric Bastiat denunciando el sistema de aranceles proteccionistas que gracias al monopolio del estado crea una "guerra de opresión recíproca, en la que el gobierno presta su autoridad a todos contra todos» (Rothbard, 1999, p. 430). El profesor Huerta de Soto puntualiza que probablemente se puede considerar a Turgot como uno de 
los verdaderos fundadores de la ciencia económica» (Huerta de Soto, 2000, p. 62).

XII

LAS APORTACIONES MÁS IMPORTANTES

DE A.R.J. TURGOT A LA TEORÍA ECONÓMICA

\section{Primero}

En la «Elegía a Gournay» (1759): Turgot demuestra su declaración más clara y ferviente a favor del laissez-faire y del librecambio. En contra de la regulación del comercio declara que todas «las restricciones olvidan que toda transacción comercial no puede menos de ser recíproca y que es absurdo tratar de vender todo a los extranjeros sin comprarles nada a cambio» (Rothbard, 1999, p. 427). Añade también que «todas esas regulaciones e impuestos suponen siempre gastos, y que estos gastos son siempre un impuesto sobre la mercancía y, como consecuencia, sobrecargan al consumidor interior y al comprador extranjero» (Rothbard, 1999, p. 428).

Al igual que haría posteriormente Adam Smith, subrayaba que el motor de todas las transacciones y el progreso estriba en el interés personal que en una sociedad libre hace que se atiendan del mejor modo posible los intereses del prójimo ya que para incrementar sus patrimonios deben ofrecer buenos servicios a terceros. Por ende, en este contexto, el interés personal siempre coincide con el interés general puesto que «es la única manera de asegurar, por un lado, el precio suficiente para estimular la producción y, por otro, que el consumidor obtenga la mejor mercancía al precio más bajo posible». Además se oponía al control de precios ya que escribía que «el gobierno debe proteger siempre la libertad natural del comprador a comprar y del vendedor para vender» (Benegas Lynch, 2009). 


\section{Segundo}

Turgot articula el carácter disperso del conocimiento que incorporan las instituciones sociales entendidas como órdenes espontáneos; es un avance de investigación de lo que desarrollaría posteriormente F.A. Hayek. Así en su «Elegía a Gournay» (1759) dice que «no es preciso probar que cada individuo es el único que puede juzgar con conocimiento de causa el uso más ventajoso de sus tierras y es esfuerzo. Solamente él posee el conocimiento particular sin el cual hasta el hombre más sabio se encontraría a ciegas, aprende de sus intentos repetidos, de sus éxitos y de sus pérdidas, y así va adquiriendo un especial sentido para los negocios que es mucho más ingenioso que el conocimiento teórico que pueda adquirir un observador indiferente, porque está impulsado por la necesidad» (Huerta de Soto, 2000, p. 62; Rothbard, 1999, p. 427).

Turgot se refiere repetidamente al conocimiento disperso que no puede ser sustituido por ninguna autoridad: no hay necesidad de probar que cada individuo es el único juez competente acerca del uso [de lo suyo]. Solo el tiene el conocimiento particular y la persona más sabia solo podría argumentar a ciegas con el [...] Resulta completamente imposible el dirigir a través de reglamentaciones y continuas inspecciones la multitud de transacciones que por su inmensidad no pueden ser conocidas las que dependen de infinidad de circunstancias cambiantes que no pueden ser manejadas ni previstas (Benegas Lynch, 2009).

\section{Tercero}

Turgot mantuvo la misma postura que los fisiócratas en dos cuestiones: en la libertad de comercio y en la demanda de la existencia de un impuesto único sobre el producto «neto» de la tierra. Aunque es destacable su amor hacia el laissez-faire dentro del comercio, se puede «entender» también que demande un impuesto único sobre la tierra y que desaparecieran el resto de impuestos existentes en otras áreas. Según Rothbard «...uno tiene la impresión de que su verdadero deseo era deshacerse de los impuestos sofocantes en todos los demás campos de la vida, más bien que imponerlos 
sobre la tierra agrícola». Por tanto es comprensible su postura cuando en aquel tiempo más de la mitad PIB procedía del factor tierra (Rothbard, 1999, p. 430).

Hay una interesante observación que realiza Turgot sobre opiniones de Gournay acerca del comercio holandés. Turgot comenta el gran elogio que realiza su maestro sobre el comercio y las ferias holandesas y como «en Holanda no hay ferias en absoluto, sino que toda la extensión del Estado y todo el año son, por así decirlo, una feria permanente, porque en ese país el comercio florece siempre y en todo lugar» (Rothbard, 1999, p. 429). Esto recuerda a la cita de Monstequieu que expresa que el «dulce comercio» destruye los «prejuicios destructores», conduce a la paz y pule las costumbres bárbaras (Montesquieu, 1997, Leyes, XX, 1, p. 214).

\section{Cuarto}

Turgot defendía que los fraudes debían ser castigados pero enfatizaba que los procesos abiertos sirven de aprendizaje a las partes; así «el consumidor que es trampeado aprenderá por experiencia y cesará de comprarle al comerciante tramposo quien perderá su reputación». Y en este mismo sentido subraya que «el pretender que el gobierno prevenga los fraudes sería como querer que se entreguen almohadas para todos los niños que pudieran caerse [...] Se pierde de vista que todas las regulaciones son confiadas a hombres que pueden tener más interés en cometer fraudes o en convivir con el fraude ya que el fraude que cometerían estaría cubierto por el sello de la autoridad pública [...] y consecuentemente la nación estará cargada con el peso para salvar a gente indolente que no se toman el trabajo de averiguar ellos al efecto de no ser trampeados» (Benegas Lynch, 2009).

\section{Quinto}

Realizó una aportación básica que fue la ley de las proporciones variables o lo que es lo mismo, la ley de los rendimientos decrecientes. Específicamente Turgot nos indica en un contra-artículo que 
realiza contra el primer ganador de un concurso sobre ensayos de tributación indirecta (Saint-Péravy), en el cual éste (de corriente fisiocrática) defendió que hay una proporción fija en los diversos gastos de las diferentes clases de la gente. Asi Turgot nos comunica que estas proporciones no son fijas sino variables dado que no existen proporciones constantes de los factores de producción (Rothbard, 1999, p. 435).

\section{Sexto}

El escritor francés hace referencia a los pseudoempresarios que viven de las protecciones de la competencia que le brinda el poder político a contramano de los intereses de los consumidores, apunta que «no hay empresario al que no le gustaría ser el único vendedor de su mercancía. No existe ramo comercial en el que los que operan en él no quisieran eliminar la competencia y que no busquen algún argumento sofista para hacer creer a la gente que eso está en el interés del país, por lo menos en lo que se refiere a los productos que vienen del exterior que presentan como los enemigos del comercio nacional. Si los oímos, y los hemos oído muy seguido, todos los ramos del comercio estarían infectados de este tipo de monopolios. Estos tontos no ven los efectos [de la extensión de esa idea] a los productos locales», lo cual bautiza como «la guerra de la opresión recíproca» (Benegas Lynch, 2009).

\section{Séptimo}

Turgot nos señala la existencia en cuanto a los efectos nocivos de los siempre crecientes gravámenes sobre la producción y el consumo, y concluye que «parece que las finanzas públicas, como un monstruo voraz, está al acecho para hacerse del botín de la riqueza de la gente» (Benegas Lynch, 2009; Rothbard, 1999, p. 430). 


\section{Octavo}

El autor francés se anticipa a la teoría subjetiva del valor y a la idea de los costes de oportunidad al enfatizar «las cambiantes necesidades de las personas» y que el valor «no es susceptible de medición». Añade que «el agua a pesar de la necesidad que hay por ella y de la multiplicidad de satisfacciones que proporciona al hombre, no se valora ya que la encuentra en abundancia». Además indica que «la superioridad en el valor de lo que estima y adquiere una persona respecto de lo que entrega a cambio, resulta esencial en el intercambio y el solo motivo del mismo» (Benegas Lynch, 2009). Según Rothbard, Turgot llega a una versión rudimentaria de que todos los costes son verdaderamente "costes de oportunidad», sacrificios que privan de cierta cantidad de recursos que podría haberse aplicado en otra parte (Rothbard, 1999, p. 432; Huerta de Soto, 2001, p. 46).

\section{Noveno}

Turgot es el precursor de la teoría de la utilidad marginal en un artículo inacabado que se titula «Valor y Dinero» en el que vislumbra «que los valores subjetivos de los bienes han de ser ordinales y no están sujetos a medida (y, por lo tanto, a la mayor parte de los procedimientos matemáticos» (Rothbard, 1999, p. 431).

\section{Décimo}

Turgot analiza e incorpora la palabra «expectativas» como concepto clave de las acciones que existen en todo mercado (Rothbard, 1999, p. 434). De este modo Huerta de Soto incluiría las expectativas como uno de los elementos esenciales que forman parte de toda función empresarial (Huerta de Soto, 2001, p. 46). 


\section{Décimoprimero}

Tiene notables nociones sobre la teoría del capital, el ahorro y el rol del interés que están en perfecta línea con las tesis de la Escuela Austriaca (lo cual incluye críticas muy bien fundadas a las leyes sobre la llamada «usura»). Turgot escribió una de sus últimas aportaciones que fue el «Escrito sobre el préstamo y el interés» donde completa su teoría del interés y se pregunta: ¿por qué los prestatarios están dispuestos a pagar la prima del interés por el uso del dinero? Turgot nos señala a saber distinguir la diferencia de utilidad que existe entre el momento en que se pide prestada una cantidad que se posee en el presente y una suma que ha de recibirse en fecha distante. Turgot incorpora implícitamente el concepto de preferencia temporal (Benegas Lynch, 2009; Rothbard, 1999, p. 441).

La gran aportación de Turgot es su concepción sobre la teoría del capital y del interés que después desarrollaría Böhm-Bawerk en la cual la idea principal dada es la siguiente; y es que no se puede invertir lo que previamente no se ha ahorrado. En sus «Reflexiones», Turgot señalaba que la riqueza se acumula por la producción anual no consumida y ahorrada. Esta idea es recogida además de por los economistas de la escuela austriaca, por los economistas clásicos aunque con una diferencia. El capitalistaempresario no sólo tendría que disponer de capital sino que además sufría la propia incertidumbre que provoca el mercado. Por tanto no se refiere a cualquier empresario o capitalista, sino que combina ambas funciones (Rothbard, 1999, p. 436). Turgot muestra que la incertidumbre inerradicable se minora gracias a las instituciones, después desarrolladas teóricamente por Carl Menger (Huerta de Soto, 2001, p. 46).

\section{Décimosegundo}

Su concepción monetaria es muy clara y queda expuesta del siguiente modo: «El dinero no es para nada el resultado de una convención por lo que se intercambia por otros valores; es en si mismo un objeto de comercio, una forma de riqueza porque tiene un 
valor» (Benegas Lynch, 2009). Según el propio Rothbard, el intelectual francés fue categórico al expresar que él no concibe el dinero puramente como signo convencional de riqueza (Rothbard, 1999, p. 443).

\section{Décimotercero}

Proclamaba a los cuatro vientos la trascendencia de la tolerancia religiosa como consubstancial a la paz: «Si imponemos la unidad religiosa y no las diferentes opiniones toleradas, produciremos problemas y guerra civil» (Benegas Lynch, 2009).

\section{Décimocuarto}

Se oponía al servicio militar obligatorio que respaldaba en el hecho de que «la repugnancia al servicio en la milicia está muy generalizada entre la gente» (Benegas Lynch, 2009).

\section{REFERENCIAS BIBLIOGRÁFICAS}

Arrow, K.J. (1951): Social Choice and Individual Values, John Wiley \& Sons, New York.

Beltrán, L. (1987): Estudio introductorio al Tratado y discurso de la moneda de vellón del P. Juan de Mariana, Instituto de Estudios Fiscales, Madrid. Versión original publicada y titulada "El Padre Juan de Mariana» en La Ilustración Liberal: Revista Española y Americana, N.o 11, (junio 2002), http:/ / www.lailustracionliberal.com/.

Benegas Lynch, A. (2009): Turgot y el laissez-faire, America's Daily, http://www.diariodeamerica.com/front_nota_detalle. php?id_noticia $=5517$.

CRISTALdo Ayala, P. (2006): «Las raíces del capitalismo», Suplemento de Ideas de la Revista de Libertad Digital en http:/ / revista.libertaddigital.com/las-raices-del-capitalismo1276231414.html. 
Grice-Hutchinson, M. (1989): «El Concepto de la Escuela de Salamanca: sus orígenes y su desarrollo» en Revista de Historia Económica, Año VII, N.․ 2, Suplemento.

Huerta De Soto, J. (2000): «Carl Menger y los precursores de la Escuela Austriaca» en La Escuela Austriaca: Mercado y Creatividad Empresarial, Editorial Sintesis, Madrid.

- (2001): «La Función Empresarial» en Socialismo, Cálculo Económico y Función Empresarial, Unión Editorial, Madrid.

- (2002): «La Teoría Bancaria en la Escuela de Salamanca» en Nuevos Estudios de Economía Política, Unión Editorial, Madrid. INFANTINO, L. (2000): «Max Weber: El primer parsons entre sociología y economía» en El orden sin plan: Las razones para el individualismo metodológico, Unión Editorial, Madrid, cap. VII.

Keynes, J.M. (1998): Ensayos de persuasión, Ed. Crítica, Barcelona. Montesquieu (1997): Del espíritu de las leyes, Ed. Porrúa, México. Pereña Vicente, L. (1954): La Universidad de Salamanca, forja del pensamiento político español en el siglo XVI, Salamanca.

Popescu, O. (1982): «Aspectos Analíticos en la Doctrina del Justo Precio de Juan de Matienzo (1520-1579)» en La Economía como disciplina científica: ensayos en honor del profesor Dr. Francisco Valsechi, Macchi, Buenos Aires, 1982.

Rothbard, M. (1999): «La Escolástica Hispana Tardía» en Historia del Pensamiento Económico, Unión Editorial, Madrid.

Velarde, J. (2002): «La Escuela de Salamanca y José Larraz» en «La Ilustración Liberal» Revista Española y Americana, n. 11. 